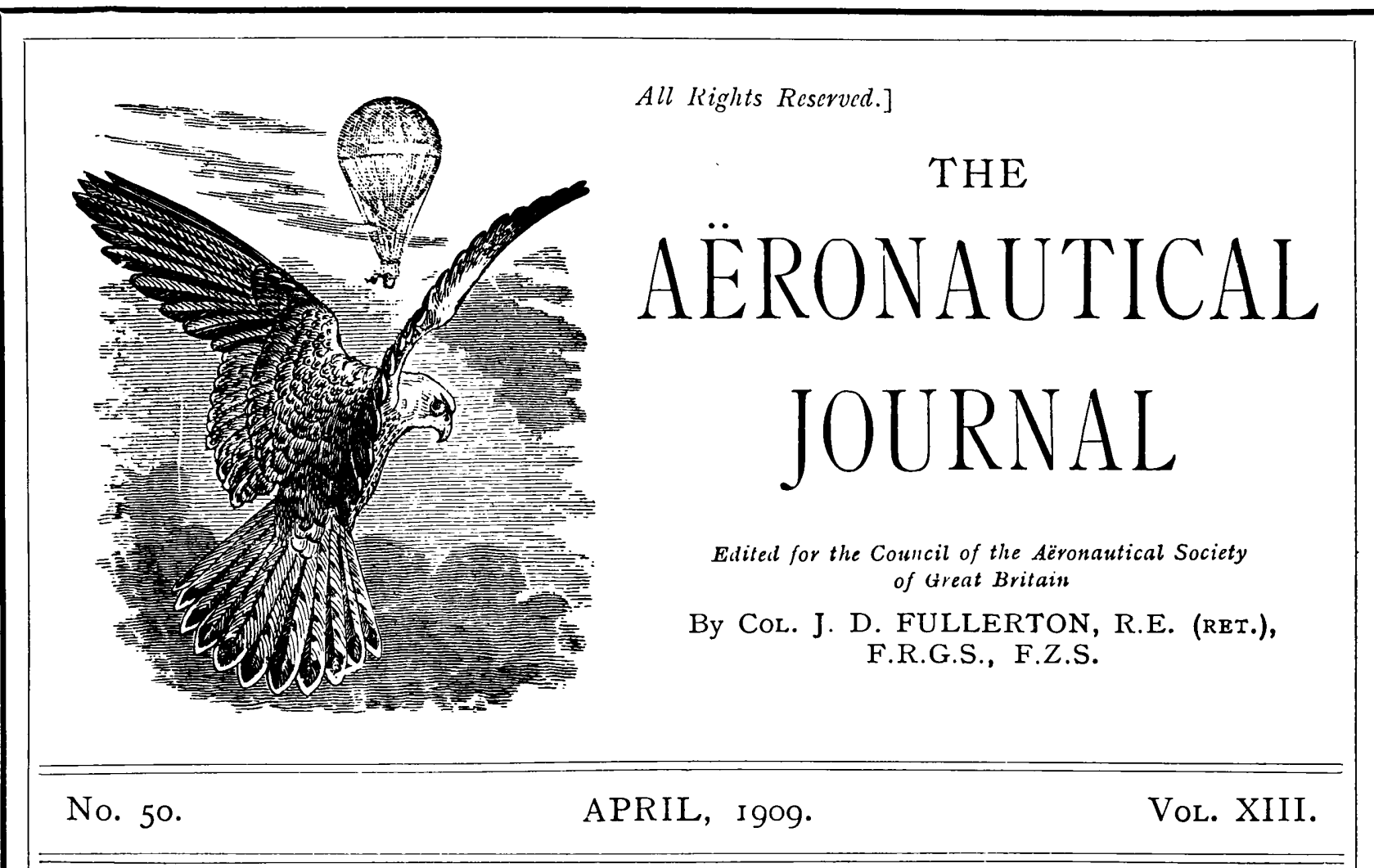

\title{
HANDLEY PAGE
}

SPECIALISTS

IN THE

\section{DESIGN}

AND

\section{LONDON}

OFFICE: 72, VICTORIA ST., S.W.

WORKS : WOOLWICH, S.E.

\section{EvERYTHING AERONAUtical}

LONDON: Published by the Ä̈ronautical Society of Great Britain, and Printed by KING, SELI \& OLDING, LTD., 27, Chancery LANE, W.C. 


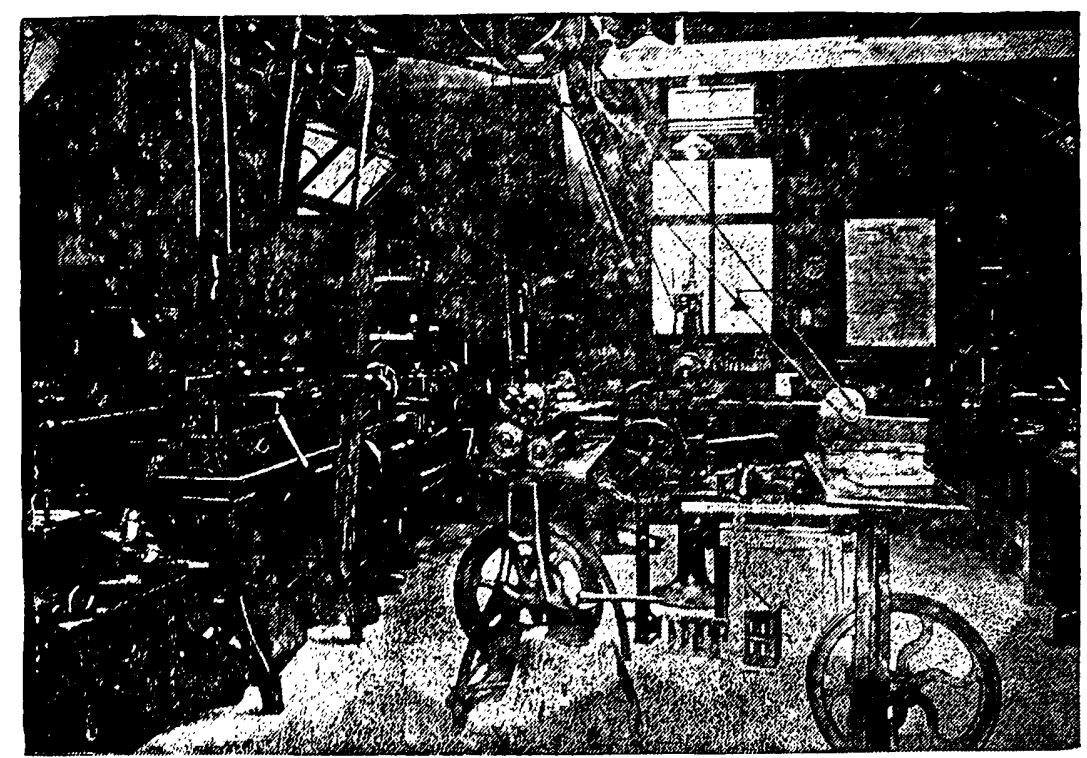

H. W. LANE,

Model Engineer.

26. Penge Road, South Norwood LONDON, S.E.

Aeroplanes constructed.

Hodels made. Inventors' experiments conducted in strict confidence.

WORKER IN MAGNALIUK

AND OTHER LIGHT METALS.

Well-equipped priyate rorkrooms ayailable for Clients, personal use.

DATENTG Messrs. RaYNeR \& Co. (G H. Rayner \& A. M. Glass, B Sc. Lond.), Patent P LI L. Agents, 37, Chancery Lane, London, W.C., pay special attention to Aeronautical Inventions. Reasonable terms arranged. Pamphlet of information Post Free.

\section{E. S. B. MACKENZIE-HUGHES,} AERONAUTIC MECHANICAL ENGINEER, 14, Howlck Place, Victoria St., Westminster, London, S.W.

Designing and Draughting undertaken. Drawings prepared to requirements of Inventors. Also Patent Drawings and Specifications drawn up.

\section{MODELS AND FULL SIZE MACHINES CONSTRUCTED TO ANY DESIGN.}

All Work undertaken and carried out strictly in private for each Client. PERSONAL, ASSISTANCE GIVEN IF REQUIRED.

3 Years' good experience in this class of work.

\section{EVEN IF YOU FLY}

\section{But DON'T use a FOUNTAIN PEN}

You are not Up=to-Date

We are willing to forward on receipt of 5s. one of our SELFFILLING and SELF-CLEANING FOUNTAIN PENS, fitted with 14-carat Solld Gold Nib.

THIS PEN IS GUARANTEED FOR RELIABILITY, EVEN FLOW, AND SMOOTH WRITING

WILLIAMS \& CO., 81, Chancery Lane, London 


\section{FOR BALLOONS AND AEROPLANES}

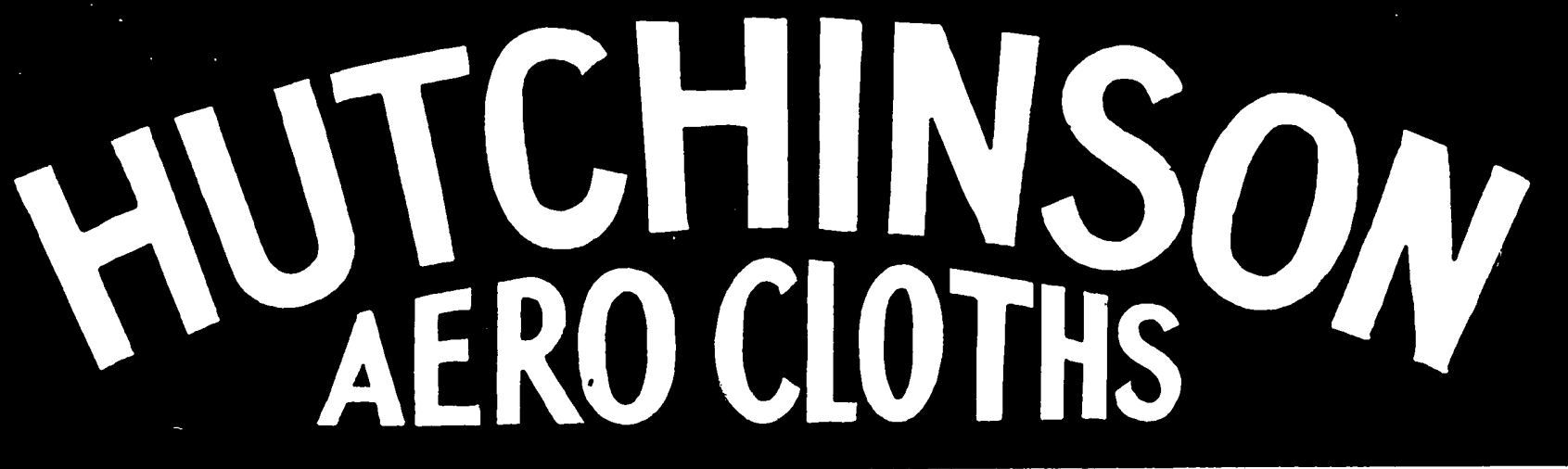

GRAND PRIZE :

FRANCO-BRITISH EXHIBITION

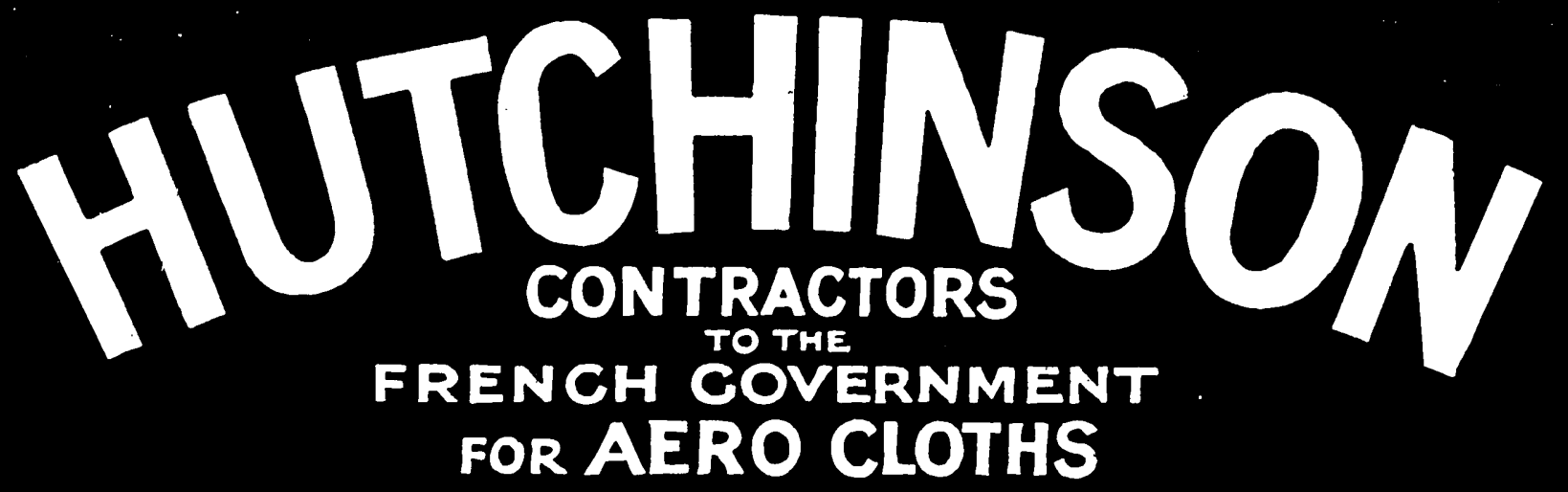

BEFORE MAKING ENQUIRIES

ELSEWHERE, COMMUNICATE WITH

AERO CLOTHS MOTOR TYRES

CYCLE TYRES
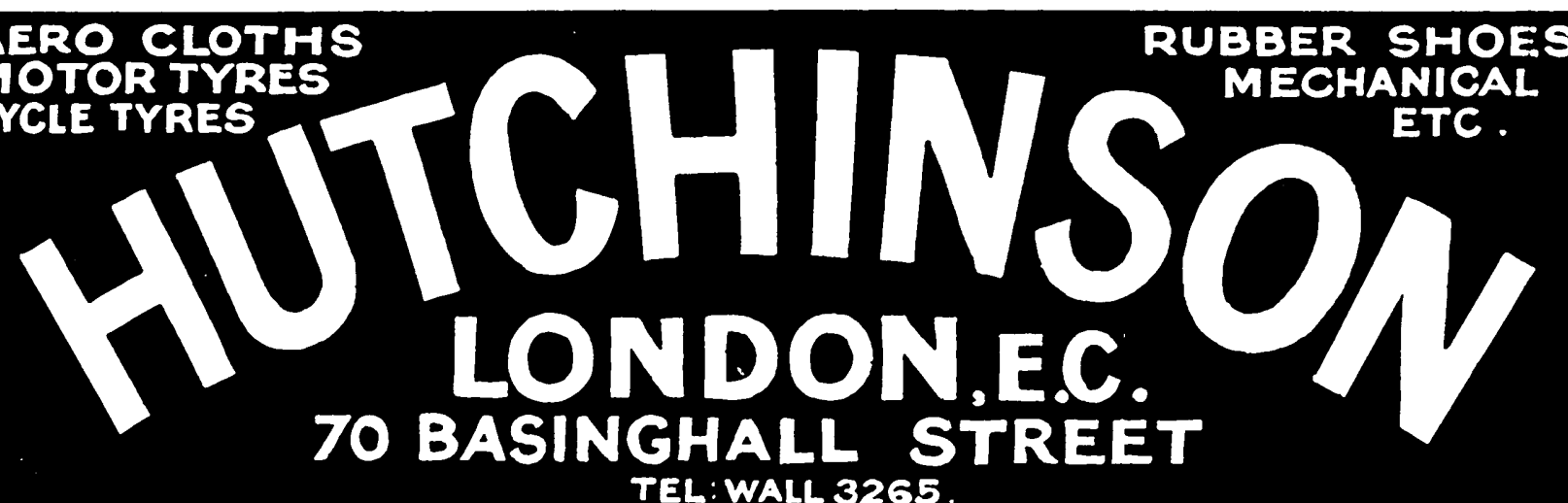

TEL: WALL 3265.

LISTS POST FREE ON APPLICATION. 


\section{BOOKS FOR AERONAUTS}

AERIAL FLIGHT By F. W. LANCHESTER. In Two Volumes. Demy 8vo, Illustrated. 21/-net each.

\section{Vol. I. AERODYNAMICS}

Dealing with the theory of Aerodynamic support and the resistance of bodies in motion in a fluid.

\section{Vol. II. AERODONETICS}

Dealing with the maintenance of equilibrium, and with the phenomenon of soaring.

"We can cordially recommend the work as an introduction to the theory of hydrodynamics by an engineer who approaches the subject from an engineer's standpoint."-Engineering.

"This is a very interesting book, and should be read by all who wish to get a good general idea of the principles of aviation."-Aeronautical Journal.

\section{AIRSHIPS, PAST AND PRESENT}

Together with Chapters on the Use of Balloons in connection with Meteorology, Photography, and the Carrier Pigeon.

By A. HILDEBRANDT, Captain and Instructor in the Prussian Balloon Corps. Translated by W. H. STORY.

Copiously Illustrated. Demy 8vo. 10/6 net.

\section{THE INTERNAL GOMBUSTION ENGINE}

Being a Text Book on Gas, Oil, and Petrol

Engines for the use of Students and Engir əers.

By H. E. WIMPERIS, M.A., Assoc.M.Inst C.E., Assoc.M.Inst.E.E.

Illustrated. Crown 8vo. 6/- net.

Those who wish to understand something of the construction and applications of Heat Engines which work on the internal combustion principle will find this an invaluable book.

PROSPECTUSES ON APPLICATION.

ARCHIBALD CONSTABLE \& Co., Ltd., io, Orange Street, Leicester Sq., W.C.

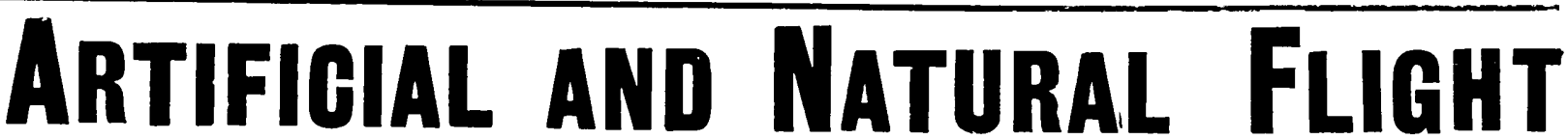

A Practical Handbook on Flying Machines, \&c.

By SIR HIRAM MAXIM.

WITH 95 ILlUSTRATIONS. Demy 8vo, price 5s. net.

CONTENTS.-Air Currents and the Flight of Birds-Flying of Kites-Screws-Experiments with Apparatus attached to a Rotating Arm-Hints as to the Building of Flying Machines-Steering by means of a Gyroscope-Shape and Efficiency of Aeroplanes-Action of Aeroplanes and the Power required-Some Recent Machines-Balloons, \&c., \&c.

"This is a thoroughly practical book . . . it is to be highly recommended to those studying the question." -

Aeronautics.

\section{A POCKET-BOOK OF AERONAUTICS}

By H. W. L. MOEDEBEGK.

In collaboration with O. CHANUTE and others. Translated from the German by Dr. W. MANSERGH VARLEY. WITH 150 ILLUSTRATIONS.

IOs. 6 d. net.

"Will be highly welcome to all aeronauts. It may be said to be the only complete work practically dealing with such matters. We have no hesitation in thoroughly reconmending this as an absolutely indispensable book." - KNowLEDGE.

WHITTAKER \& C0., 2, White Hart Street, Paternoster Square, LONDON, E.C.

\section{A TRIUMPH OF REALISTIC IMAGINATION}

\section{AT ALL BOOKSELLERS AND LIBRARIES, 6S.}

\section{THE WAR
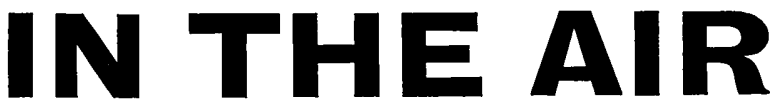

By H. G. WELLS

With Sixteen Illustrations by A. C. MICHAEL.

"Mr. Wells gives us to perfection a wonderful sense of being in the airships, moving with them, and participating in the deadly and ruthless war in which they are engaged. . . He has to paint a picture of what an aerial battle will be. No man knows, but the ingenuity, the daring, the colour. confusion, and horrible chaos of these detached and bewldering scenes almost convince us that Mr. Wells does know." -Athenceum.

London: GEORGE BELL \& SONS, York House, Portugal Street, W.C.

SPECIAL NUMBER OF THE AËRONAUTICAL JOURNAL, JANUARY, 1907

There are a limited number of copies left of this number, which contains Dr. William Napier Shaw's paper on "The Use of Kites in Meteorological Research," with specially prepared diagrams. 